\title{
LA BAHÍA DE CÁDIZ EN EL CONTEXTO DEL MUNDO PÚNICO: ASPECTOS ÉTNICOS Y POLÍTICOS
}

\author{
THE BAY OF CÁDIZ WITHIN THE CONTEXT OF THE PUNIC WORLD: \\ ETHNIC AND POLITICAL ASPECTS
}

\author{
EDUARDO FERRER ALBELDA ${ }^{1}$
}

A Roberto Mateos

In memoriam

Resumen: Analizamos a partir de los datos literarios griegos y latinos y de la documentación arqueológica la complejidad étnica y política del entorno de la bahía de Cádiz, con la ciudad de Gadir como protagonista. Proponemos que la colonización fenicia y los fenómenos de mestizaje y aculturación con las poblaciones locales de esta área configuraron un sustrato demográfico y cultural mestizo con zonas de predominio fenicio, como el entorno de la bahía, y otras de mayoría tartesia-turdetana conviviendo con comunidades fenicias. La literatura posterior a la conquista romana (Estrabón, Mela, Plinio, Ptolomeo) denominó a las poblaciones de origen semita con el étnico bastetano o bástulo, habitantes del litoral atlántico y mediterráneo de la actual Andalucía, y diferenciadas étnicamente de las turdetanas. En lo que se refiere a los aspectos políticos, sugerimos una delimitación territorial de Gadir centrada en el territorio insular y en litoral de la bahía, fronteriza con dos formaciones estatales como Asta Regia y Asido, y sometemos a crítica el concepto de "liga púnico-gaditana" por el cual Gadir se erige con el liderazgo de las antiguas colonias fenicias de Iberia. En nuestra opinión, ese papel lo adquiriría la ciudad tras la conquista romana.

Palabras clave: Gadir, etnicidad, contexto político, período púnico

El título con el que hemos encabezado el artículo es ya una declaración de intenciones con la que

1. Departamento de Prehistoria y Arqueología, Universidad de Sevi1la. Proyecto Sociedad y paisaje. Análisis arqueológico del poblamiento

\begin{abstract}
Using data from Greek and Roman texts and from the archaeological record, we analyse the ethnic and political complexity of the bay of Cadiz, with particular emphasis on the city of Gadir. We suggest that the Phoenician colonisation and the phenomena of mixture and acculturation of the local populations of this area shaped a demographic and cultural basis with areas of Phoenician dominance, for instance in the area of the bay, and others of tartessian-turdetanian majority that coexisted with Phoenician communities. The literature after the Roman conquest (Strabo, Mela, Pliny, Ptolemy) named Bastetanians the populations of Semitic origin living in the Atlantic and Mediterranean littoral of present-day Andalusia (Spain) which were ethnically different from the Turdetanians. In relation with political issues, we suggest a delimitation of the territory of Gadir, in the insular area and littoral of the bay, which acted as a frontier with the state formations of Asta Regia and Asido. We critique the concept of the "gaditanian-punic league" in which Gadir would have led the ancient Phoenician colonies of Iberia. In our opinion, the city would only have acquired that role after the Roman conquest.
\end{abstract}

Key word: Gadir, Ethnicity, political context, punic period

pretendemos insistir en la idea de una completa integración del Extremo Occidente en la dinámica histórica del

rural en el sur de la Península Ibérica (siglos VIII a.C.-II d.C.), Ministerio de Educación y Ciencia (HUM-2005-07823). 
Mediterráneo, y concretamente del "mundo púnico", entendiendo como tal la configuración de una cultura mediterránea heterogénea pero con rasgos comunes, como la herencia demográfica y cultural de la colonización fenicia, la emancipación política y económica de la metrópoli desde el siglo VI a.C., la configuración de diversos "círculos" (Cartago, Gadir) por la concurrencia de intereses políticos, económicos y religiosos (Arteaga 1990; 1994; 2001; Ferrer 1996; 1998; 2002-2003: 16), y la evolución política de éstos desde la independencia hacia una creciente hegemonía y política intervencionista de Cartago que fraguó en la conquista cartaginesa del sur y este de Iberia (G. Wagner 1985; 1994).

No obstante, esta noción de integración de la bahía de Cádiz en el mundo púnico colisiona con no pocos problemas conceptuales y con algunas interpretaciones relativamente recientes pero ya asentadas en el panorama historiográfico hispano referidas al origen étnico y a las formas de organización política de estas comunidades. En el primer aspecto, la confusión proviene de la atribución indiscriminada de etnónimos como púnicos, libiofenicios o turdetanos a determinadas áreas geográficas y yacimientos arqueológicos, de manera que el Castillo de Doña Blanca, una colonia fenicia de época arcaica, considerada por su excavador como la genuina Gadir (Ruiz Mata 1998), es definida también como una ciudad turdetana (Ruiz Mata 1987), o sea un asentamiento integrado en una cultura homogénea conformada por la interacción entre fenicios y tartesios que han asimilado el impacto cultural semita durante el período orientalizante (Ruiz Mata 1997 y 1998; la crítica a este planteamiento en García Fernández 2002a: 222; y e.p.).

El problema que conlleva esta interpretación no es la aceptación del mestizaje biológico y cultural entre las poblaciones tartesias y fenicias, ni de la existencia de comunidades mixtas (Bandera y Ferrer 1995; Belén y Escacena 1995; González Wagner 2005: 159), sino la renuncia a la posibilidad de diferenciar mediante criterios arqueológicos, literarios o filológicos dos o más grupos étnicos en el área tartesia-turdetana, asumiendo la existencia de una "cultura turdetana" común que sería una amalgama de ingredientes fenicios e indígenas. La repercusión de esta propuesta ha trascendido más allá de las fronteras de la propia Turdetania, y se ha propuesto incorporar a las comunidades del Algarve portugués a esta koiné turdetana dadas las similitudes del registro arqueológico entre ambas costas, cuando los testimonios literarios son insistentes en la habitación de la región por conios o cunetes, y la cultura material es indicativa de un sustrato fenicio sobre el que incidió la integración de estas comunidades en el "Círculo del Estrecho" (Arruda 1999-2000; Arruda y otros 2005).

Esta problemática ha sido abordada por F.J. García Fernández (2002a; 2002b; 2003; Ferrer y García Fernández 2002) en distintas ocasiones, y a sus principales conclusiones nos remitimos. Primeramente habría que discriminar los conceptos "Turdetania", "turdetanos" y "cultura turdetana", procedentes los dos primeros de la documentación literaria grecolatina y el tercero de la historiografía arqueológica. "Turdetania" sería un concepto literario exclusivamente geográfico "destinado a facilitar la administración de los territorios en proceso de conquista" y con una clara funcionalidad político-administrativa (Cruz Andreotti 1993; García Fernández 2002: 193); una región que sin embargo, como refiere Estrabón (3.2.13), no sólo estuvo habitada por turdetanos sino también por otras ethne como oretanos, bastetanos, bástulos, fenicios y celtas. Por su parte, "turdetanos" es un concepto étnico genérico creado por la etnografía helenística con una voluntad homogeneizadora que quizás enmascaró una realidad étnica más compleja, pues probablemente no existió una única etnia turdetana, sino un conjunto de poblaciones emparentadas lingüísticamente y con cierta afinidad cultural, pero carentes de una conciencia de unidad, como lo demuestra la ausencia de una comunidad de intereses y solidaridad de grupo a lo largo de la contienda púnica y aún menos durante los primeros siglos de la presencia romana (García Fernández 2002: 193; Chaves y otros 2006).

En tercer lugar, "cultura turdetana" es un concepto creado por la historiografía arqueológica reciente que plantea más problemas de los que soluciona pues no proporciona unas pautas culturales claras para analizar una diversidad poblacional tan evidente. Los indicadores étnicos ${ }^{2}$ que pudieran establecer diferencias netas entre unos grupos étnicos y otros serían aquellos relacionados con la organización social, con las costumbres funerarias, la religiosidad o los atributos de edad o

2. Por razones de espacio no vamos a analizar el concepto de ethnos entre los griegos ni tampoco los estudios más recientes en Arqueología sobre identidad étnica para lo cual me remito a publicaciones recientes en las que está recogida la bibliografía básica: Cruz Andreotti y Mora (2004) y García Fernández (e.p.). Pero no queremos dejar de insistir en que "los marcadores étnicos no constituyen elementos objetivos para el espectador, sino que se trata de atributos subjetivos autoimpuestos por las comunidades humanas a través de un proceso discursivo y continuo de revisión de su identidad respecto de las demás" (Chaves y otros 2006). Consecuentemente es una construcción subjetiva, generalmente fruto del auto-reconocimiento por oposición a otros, no estática, de ahí que se denomine "etnicidad activa" o "etnogénesis continua", una "constante reafirmación o rectificación de los valores identitarios de un grupo social a partir de una serie de estímulos internos y/o externos y dentro de un proceso histórico" (García Fernández e.p.). 
de sexo, aquellos precisamente que el registro arqueológico se resiste a mostrar (Escacena 1989 y 1992; Ferrer y García 2002; García Fernández e.p.).

La diversidad étnica del entorno de la bahía de Cádiz durante el Ir milenio a.C., como de otras áreas de Turdetania, es un hecho incontrovertible, aunque del proceso histórico que la configura se conozca mejor el epílogo, después de la conquista romana. Por ejemplo, Estrabón (3.1.7), que utilizó datos autópticos, de testigos presenciales como Polibio o Posidonio, refiere que los habitantes del área del estrecho de Gibraltar se denominan bastetanos o bástulos, de hecho Carteia era un importante puerto bastetano. Asimismo los bastetanos pueblan Turdetania: la franja costera que se extiende desde Gibraltar hasta la desembocadura del río Guadiana (3.2.1) y el litoral desde las Columnas de Heracles hasta Cartago Nova (3.4.1). Coinciden en la noticia Plinio (NH 3.8 y 19), al considerar que las costas del sur de Iberia están habitadas por bástulos, y Pomponio Mela (2.96), autor oriundo de Tingentera, para el cual la costa atlántica de la Bética está poblada por bástulos y túrdulos.

No es la primera vez que planteamos la identificación de estos bastetanos o bástulos con las comunidades fenicio-púnicas de Iberia, hipótesis sustentada por la existencia de determinados etnónimos mixtos como "blastofenicios", "bástulo-poenos" y "bástulos llamados púnicos", transmitidos por Apiano (Iber. 56), Marciano de Heraclea (2.9) y Ptolomeo (2.4.6) respectivamente. Y tampoco es una primicia sacar a colación un conocido pasaje de Estrabón (3.2.13) en el que deja constancia de la importancia numérica de los fenicios en la composición étnica de Turdetania, pues la mayoría de sus ciudades y las de las regiones vecinas estaban habitadas por ellos (Ferrer 1996b; 1998; 2004; Ferrer y Prados 2001-2002). El origen de esta situación, característica de los siglos II-I a.C., se remontaría a la colonización fenicia, un proceso histórico prolongado en el tiempo que no sólo se nutrió demográficamente del traslado y asentamiento de poblaciones exógenas sino también de la reproducción de estas mismas y, sobre todo, del mestizaje con las poblaciones locales. En el período postcolonial el dinamismo económico de las ciudades púnicas, sobre todo las integradas en el "Círculo del Estrecho", debió contribuir notablemente a su expansión demográfica y a la formación de comunidades púnicas en las principales ciudades turdetanas como Onuba, Ilipla, Nabrissa, Asta Regia, Ilipa o Carmo (Ferrer 2004; Chaves y otros 2006) ${ }^{3}$.

3. No compartimos, sin embargo, la idea de traslados y asentamiento masivo de contingentes de libiofenicios y númidas antes,
Por tanto la población de la bahía de Cádiz debió ser de origen fenicio mayoritariamente, situación étnica que también puede atribuirse a otras áreas de Turdetania, como la costa mediterránea y el litoral atlántico, que comparten un antiguo sustrato colonial fenicio. Los rasgos identitarios que diferenciarían a los púnicos de los turdetanos serían, además de aquellos que los etnógrafos y geógrafos antiguos percibieron para establecer la división étnica que transmitieron, y que desconocemos, la consciencia de un origen común, de un pasado que los hace oriundos de Canaan ${ }^{4}$, la comunidad de lengua y de alfabeto, la creencia en un mismo sistema cosmogónico y escatológico, con similitudes en el panteón y en los cultos $\mathrm{y}$, aunque no de forma exclusiva, el predominio de un tipo de formación política muy característica de la cultura fenicio-púnica y propio de las sociedades de tradición urbana próximo-orientales, la ciudad-estado.

El litoral mediterráneo y atlántico de Turdetania constituiría, pues, el área nuclear de la cultura púnica de Iberia, pero no el único espacio habitado por ellos. Una de las características de la identidad étnica, además del constante cambio en su autodefinición, es su dinamismo y movilidad geográfica, y ahí es donde radica la dificultad en delimitar unas fronteras étnicas nítidas en sincronía y en diacronía. En esta problemática también concurre la convivencia de distintos grupos étnicos en un mismo territorio, incluso en un mismo asentamiento, un fenómeno comprobado en el área meridional de Iberia no sólo en el época protohistórica sino también, dado el incremento de la información literaria, en los primeros siglos de la presencia romana ${ }^{5}$.

El litoral portugués y onubense, la Tierra Llana, las riberas del sinus tartesius, la campiña y la serranía de

durante y después de la segunda Guerra Púnica; la argumentación en Ferrer (2000).

4. Como es el caso de las poblaciones campesinas norteafricanas de la Antigüedad tardía, que se consideraban cananeas todavía en tiempos de Agustín de Hipona (Epistolae ad Romanos inchoata expositio 13). Los comentarios en Ferrer (1996: 128) y López Castro (2004: 156-157). En el caso de Gadir, la leyenda fundacional de la ciudad transmitida por Estrabón (3. 5. 5) y por Justino (44. 5) sería la historia "oficial" de la ciudad, probablemente cocinada en el templo de Melqart, y nos da una idea de la autoconsciencia de la población gaditana sobre su origen vinculado a Tiro y a su divinidad tutelar.

5. Volvemos a proponer como ejemplo el pasaje estraboniano referido a la presencia de fenicios en la mayoría de las ciudades de Turdetania y otras regiones vecinas. La política colonizadora romana puso en práctica la integración en un mismo asentamiento de comunidades de distinto origen cultural, como el caso de Itálica, mediante el establecimiento de los veteranos de guerra itálicos en un asentamiento turdetano (Apiano, Iber. 38), o el de Carteia, una importante ciudad portuaria púnica donde fue fundada una colonia latina en 171 a.C. (Tito Livio, 43. 3). 
Cádiz constituyeron espacios en los que la colonización fenicia en primera instancia, y posteriormente su integración en el "Círculo del Estrecho" (Chaves y García 1991; 1994), actuaron como factores de atracción de poblaciones de origen fenicio integradas entre las comunidades turdetanas y conias. La epigrafía monetal constituye, en estos casos, un elemento de valor indiscutible pues la utilización de uno u otro alfabeto indicativa del uso de una lengua determinada, ya sea del común de la población o de la elite-, no es gratuita ni arbitraria, sino que expresa el interés de las entidades emisoras en dejar constancia de su idiosincrasia, de un factor económico concreto y/o de su adhesión a una determinada política. Es sintomática, por este motivo, la distribución en Turdetania de las cecas que emiten en púnico y neopúnico (Alfaro 1991 y 1998; Chaves 2000): la mayoría son antiguas fundaciones fenicias como Gadir, Malaka, Seks y Abdera, a las que hay que añadir Tagilit, en el valle del Almanzora, vinculada a otra antigua colonia fenicia, Baria; Ituci (Tejada la Nueva, Huelva) y Olontigi (Aznalcálzar, Sevi1la), relacionadas desde los tiempos de la colonización fenicia con la metalurgia y el tráfico de metales.

Otro grupo de cecas, las erróneamente denominadas "libiofenicias", utilizó el neopúnico en una versión muy evolucionada y con claros síntomas de latinización (Solá Solé 1980; García-Bellido 1993; Alfaro 1991 y 1998; Ferrer 2000). Su distribución geográfica en dos áreas alejadas pero con antecedentes de "orientalización", la trascosta gaditana, que agrupa el conjunto más numeroso (Asido, Baelo, Iptuci, Lascuta, Oba y Vesci), y la Baeturia túrdula (Arsa y Turirecina), testimonia tanto la existencia de comunidades con una composición étnica mixta cuanto más la participación de ambas en circuitos económicos muy dinámicos -con cierta movilidad de gentes- controlados por las ciudades púnicas, como la "industria" de salazones y la extracción y comercio de la sal para el caso gaditano, o el tráfico de metales en relación con la Baeturia túrdula (Chaves y García 1991 y 1994).

"Resulta, pues, una tarea inútil el afán por establecer fronteras étnico-culturales claramente definidas, como en ocasiones se ha pretendido; de lo contrario, sería complejo justificar la perduración de elementos de tradición fenico-púnica en ciudades "turdetanas" como Ilipla, Hispalis o Carmo aún en los primeros siglos de nuestra Era. De hecho, resulta equívoco asignar a los grupos étnicos territorios estables, ya que si por algo se caracterizan es precisamente por su movilidad, es decir, la plasmación en el espacio de su propia dinámica interna, así como de sus relaciones con otros grupos. Habría que hablar, por tanto, de zonas con un predominio cultural o étnico -e incluso político-determinado, y de otras comarcas con un componente poblacional mixto, más que de unidades étnico-culturales homogéneas y estáticas" (Chaves y otros 2006).

$* * *$

La configuración de un mapa político bien definido de la bahía de Cádiz es una tarea si cabe más ardua que la delimitación del mapa étnico. Disponemos de escasos y controvertidos datos literarios, y los estudios arqueológicos, sobre todo los de territorio, además de escasos y parciales, presentan unas limitaciones evidentes a efectos interpretativos. Desconocemos, en definitiva, el estatuto político de la mayoría de los asentamientos prerromanos del área de estudio y los territorios bajo su control, así como las relaciones de subordinación entre unos y otros, apenas atisbadas en algunos documentos epigráficos.

Empezando por Gadir, ignoramos la delimitación del territorio político de la ciudad, y si, por ejemplo, el Castillo de Doña Blanca estaba integrado en su área metropolitana. Asimismo, y a pesar de disponer de algunos datos literarios y epigráficos, hay dudas justificadas sobre el tipo de vinculación, no sólo política sino también étnica, entre Gadir y una gran formación estatal del entorno, Asta Regia, que debió tener una considerable proyección política y territorial en la zona, como su mismo nombre indica (Ferreiro 1982: 168; García Moreno 1986: 203; Chic 1994). Desconocemos, en definitiva, la relación política de Gadir con otras ciudades púnicas de Iberia como Carteia y aquellas situadas tanto al este del estrecho de Gibraltar, entre ellas Malaka, Sexi y Baria, como al oeste, como Onuba (Ferrer 2004) y las ciudades prerromanas del Algarve (Baesuris, Balsa, Ossonoba) con las que mantuvo evidentes lazos económicos (Arruda 1999-2000; Arruda y otros 2005: 177 ss.; Carretero 2005).

El concepto de "Círculo del Estrecho" creado por Tarradell (1960: 61; 1967: 303 ss.; 1968) ${ }^{6}$ puede responder a la dimensión económica de un fenómeno que es sin duda evidente: la koiné económica del litoral atlántico ibérico y africano, basada en la explotación de los recursos marinos (sal, salazones y salsas de pescado) y en el tráfico de materias primas (estaño, oro, marfil) y de ciertos productos elaborados ${ }^{7}$, que configura un espacio

6. Posteriormente perfilado por autores como Ponsich (1975), Arteaga (1990; 1994, 2001), Chaves y García Vargas (1991; 1994; Chaves y otros 1998), Millán (1998), Niveau de Villedary (2001) o Domínguez Pérez (2003).

7. Las informaciones de Heródoto (4.184), pseudo-Aristóteles (Miriabilia, 136), Estrabón (3.5.11) y Avieno (O.M. 113-114), no por reiteradas menos útiles, proporcionan en sus respectivos niveles de 
económico centralizado en la bahía de Cádiz y con ramificaciones en la costa atlántica africana e ibérica ${ }^{8}$, incluyendo también las márgenes del sinus tartesius.

Pero la formulación conceptual del "Círculo del Estrecho" no respondía a la dimensión política del fenómeno al no definir claramente las características de las formaciones políticas integrantes del "Círculo del Estrecho" ni las relaciones jerárquicas entre unas y otras, si bien el papel hegemónico de Gadir y Lixus parecía fuera de toda duda. Tarradell (1967: 304), ante la concomitancia del registro arqueológico de los yacimientos fenicios hispanos y norteafricanos que tan bien conocía, y las diferencias con la cultura material de los yacimientos púnicos centro-mediterráneos, propuso distinguir dos áreas, una occidental "mucho más ligada al Mediterráneo oriental, al mundo fenicio-chipriota, y un área cartaginesa, más central, que comprende las islas de Cerdeña, Ibiza y, en gran parte, Sicilia”. El Extremo Occidente y Fenicia siguieron manteniendo relaciones comerciales después del auge de Cartago, y los ataques de babilonios y macedonios contra Tiro "debieron provocar una corriente migratoria hacia las pequeñas ciudades occidentales que habían nacido de su empuje y cuyos vínculos morales y económicos no se habían cortado" (Ibid., 308).

La argumentación de Tarradell para definir esta dualidad se basó en la ausencia-presencia de determinados productos como la cerámica de "barniz rojo", máscaras y terracotas, navajas de afeitar y, ya en época romana, la iconografía monetal. El tiempo transcurrido desde la formulación original del concepto ha sido generoso con la denominación y con la idea de una comunidad de intereses fenicios en el Extremo Occidente bajo el liderazgo de Gadir, pero implacable con su argumentación (Arteaga 1994: 25-26), porque la idea de una relación fluida entre Fenicia y las colonias semitas de Occidente con posteridad a la conquista de Tiro y al margen de Cartago se contradice con los datos literarios, con el registro arqueológico, con la lógica de la geoestrategia y con la dinámica comercial del período postcolonial.

fiabilidad histórica y de fidelidad a las fuentes originales datos valiosos sobre este tráfico atlántico desde el período arcaico hasta época republicana romana. La investigación arqueológica, por su parte, ha proporcionado datos sobre los tipos de barcos y los cargamentos, como los del pecio Bajo de la Campana I (625-575 a.C.), que transportaba entre otros productos colmillos de marfil y lingotes de estaño de indudable procedencia atlántica (Mas 1985; Martín Camino y Roldán 1991; Roldán y Martín Camino 1995; Mederos y Ruiz Cabrero 2004: 277).

8. Estudios recientes amplían el radio de acción de este tráfico comercial atlántico hasta las costas gallegas (Domínguez Pérez 2005 49 ss.; González Rubial 2004 y 2006). La mayoría de los autores incluyen también la costa mediterránea hispana y norteafricana.
La relación entre Tiro y Cartago, mejor documentada que con Gadir, fue de orden materno-filial como ponen de manifiesto numerosos testimonios literarios grecolatinos. Quinto Curcio (4.2.10) alude a los vínculos de unión entre Cartago y su metrópoli, actualizados anualmente durante siglos a través de una embajada cartaginesa que sacrificaba en el templo de Melqart en Tiro; y, como recuerda S. Lancel (1994: 46-47), estos lazos de unión "se mantuvieron tan fuertes a través de los siglos -lazos que no se documentan tan claramente en ninguna otra ciudad fenicia de Occidente- que,..., resultan casi superfluos los numerosos testimonios escritos (Diodoro 17.40; Estrabón 17.3.15; Tito Livio 33.49) que afirman que Cartago fue desde su origen una colonia oficialmente 'transferida' por Tiro"".

Del mismo modo, los elementos del registro arqueológico propuestos por Tarradell para justificar la dualidad política y económica entre Cartago y el "Círculo del Estrecho" tampoco pueden ser argumentados hoy sin un análisis más profundo. Primeramente porque las relaciones políticas son difícilmente evaluables a través del análisis arqueológico de determinados productos artesanales; éstos constituyen la evidencia de la circulación de productos y de la existencia de determinados circuitos comerciales, que son los que pueden estar condicionados por las relaciones políticas.

Por otro lado, un examen del registro arqueológico extremo-occidental sin prejuicios desmiente la idea de una especial conexión entre ambos extremos del Mediterráneo y del aislamiento del área central. La cierta homogeneidad morfológica y decorativa del repertorio cerámico fenicio arcaico en las colonias fenicias del Mediterráneo se quiebra a partir del siglo VI a.C., a la vez que se desarrollan talleres independientes que modifican y crean sus propios repertorios atendiendo

9. Pompeyo Trogo (en Justino 18.7.7) hace referencia a la entrega al Hércules tirio de parte del botín obtenido por Malco en Sicilia, y Diodoro (20.14) deja constancia de la trascendencia ideológica que tenía la concesión del diezmo de las rentas cartaginesas al santuario de Melqart, de tal manera que cuando fueron desatendidas estas obligaciones y los cartagineses sufrieron en su territorio la expedición de Agatocles (fines del siglo IV a.C.), fue restituida la ofrenda anual al dios. Asimismo, en el contexto de las guerras de Sicilia de fines del siglo V a.C., los cartagineses enviaron al santuario de Hércules en Tiro una estatua de bronce del dios Apolo que habían saqueado de Gela (Lancel 1994: 47). Otra ocasión de renovación de estos vínculos fue el asedio y posterior conquista de Tiro por Alejandro de Macedonia (332 a.C.), ante el cual Cartago no prestó la ayuda que el parentesco, los tratados y la solicitud de la ciudad fenicia requerían, pero se declaró dispuesta a acoger a mujeres, niños y ancianos de Tiro (Huss 1993: 113). El cordón umbilical que unía a las dos ciudades sólo se seccionaría con la destrucción de Cartago; años antes, según menciona Polibio (31.12), todavía las naves cartaginesas transportaban las ofrendas destinadas a los dioses de Tiro. 
a tradiciones locales y a determinadas influencias externas. Este fenómeno es singularmente perceptible en la cerámica de transporte (Ramón 1995), pero interesa a todos los grupos cerámicos. Por ejemplo, el revestimiento arcilloso denominado "engobe rojo", tan característico de época arcaica, tiende a desaparecer en todas las vajillas de las antiguas colonias fenicias; los recipientes apenas se decoran o lo hacen con sencillas bandas y líneas pintadas, y son incorporadas a la vajilla de mesa a partir del siglo IV a.C. formas y decoraciones con éxito en el Mediterráneo procedentes del repertorio cerámico ático. Es paradigmático el caso de los talleres gadiritas, indudablemente capacitados para adaptarse a las tendencias más exitosas y dispuestos siempre a satisfacer la demanda de los mercados. Un ejemplo de lo que venimos hablando lo constituye la vajilla "tipo Kuass", una producción con gran difusión y de perduración dos veces centenaria que versiona el servicio de mesa ático de barniz negro cuando éste desaparece de los circuitos occidentales, imprimiéndole una estética más adecuada a los gustos locales al estar engobadas en rojo (Niveau de Villedary 1999; 2000; 2003).

En el Extremo Occidente no se puede hablar, por tanto, de una única tradición alfarera, aunque sí de una génesis común y de ciertas tendencias generales. No disponemos de un registro arqueológico homogéneo en lo que se refiere a la documentación de talleres, pero es perceptible la distinción en la Iberia púnica de al menos tres tradiciones alfareras con una personalidad acusada: Gadir (Ruiz Mata 1987; Sáez y Díaz 2002), Malaka (Gran Aymerich 1991) y Baria (Ramón 1995); y precisamente es en las alfarerías de Gadir donde se detectan con más nitidez, y desde el siglo VI a.C., la circulación de moldes y modelos iconográficos procedentes del Mediterráneo central, tendencia que perdurará hasta los siglos de la romanización. La producción de terracotas y máscaras gadiritas, hasta hace poco intuidas y hoy bien documentadas, siguen fielmente las directrices marcadas por los centros alfareros siciliotas y cartagineses (Ferrer 1995-96; Ferrer y otros 2000; Bernal y otros 2003; Bernal y otros 2005).

Un último aspecto, en el que no abundaremos, es el de las razones geoestratégicas y de organización del comercio transmediterráneo que hacen improbable la interpretación que propusiera Tarradell. A partir del siglo VI a.C. el sistema comercial basado en las relaciones coloniales entre Oriente y Occidente desapareció al mismo ritmo que el comercio aristocrático se estaba transformando en comercio "administrado" (Arteaga 2001: 244). El alejamiento geográfico, los problemas internos de las metrópolis, la propia dinámica política del Mediterráneo oriental (guerras médicas, liga ático- délica, etc.), el surgimiento de nuevas y poderosas entidades estatales (Cartago, Siracusa, Massalia, algunas ciudades-estado etruscas, Roma, Gadir), hicieron que las antiguas relaciones coloniales se redujeran casi a vínculos sentimentales. El llamado comercio "administrado" o "gerencial" sería el que coordinaría las relaciones entre los estados a través de tratados, en los que se especificaban las áreas abiertas y cerradas al comercio y a la colonización, los puertos donde se realizarían las transacciones, los fedatarios públicos encargados de la vigilancia de los intercambios y de las pesas y medidas, así como del cumplimiento de los reglamentos (González Wagner 1984; Fernández Nieto 1992; Ferrer y García Vargas 2001).

De la exposición de estos argumentos podemos extraer dos conclusiones: en primer lugar que la vinculación entre Gadir y Tiro no debió ser mayor -si acaso menos estrecha- de la que pudo tener Cartago con la metrópoli; y en segundo lugar, que la lectura del registro arqueológico parece insistir en esta misma noción: la acusada personalidad de las producciones artesanales extremo-occidentales no implica que no haya una conexión fluida y continua con los talleres centro-mediterráneos al estar ambos insertos en los mismos circuitos comerciales.

Más o menos definida la dimensión económica del "Círculo del Estrecho", faltaba por caracterizar una dimensión política que fuese más allá del asumido liderazgo de Gadir. Con el objeto de cubrir este vacío, O. Arteaga (1994) formuló hace una década una nueva propuesta que sí abordaba la dimensión política, la de la existencia de una "liga púnico-gaditana", que situaba a Gadir en el epicentro político del "Círculo del Estrecho" y que articulaba las relaciones políticas de las ciudades-estado púnicas mediante pactos bajo el liderazgo gadirita, apostando por un desarrollo histórico extremo-occidental desligado del devenir de otros fenómenos políticos como Cartago, estado con el que Gadir mantendría relaciones de igualdad, no de subordinación. La "Liga de Gadir" sería un "producto económico-político-religioso del concepto colonial del Círculo del Estrecho" surgido tras la ruptura de la soberanía de Tiro por la consolidación de los emergentes poderes occidentales y la promoción de sus respectivos sistemas ciudadanos que renovarían los pactos políticos en la "Liga de Gadir" (Arteaga 1994: 26). Las poleis púnicas se integrarían en esta liga bajo el patrocinio del Heracleion de Gadir con el objetivo de limar problemas territoriales (definición de fronteras ciudadanas) y marítimos (reparto de circuitos mercantiles), de manera que desde los siglos V y IV a.C. la polis gadirita impuso una hegemonía que afectaría incluso al 
"reborde de las tierras turdetanas", "donde se observa este crecimiento socio-económico adscrito al círculo productivo de Gadir" (ibid. 43 y 46).

La de O. Arteaga es una propuesta sugerente, bien argumentada en lo que se refiere a su contextualización histórica por la utilización como modelos comparativos de manifestaciones políticas contemporáneas como la liga ático-délica y los tratados concluidos entre Cartago y Roma desde fines del siglo VI a.C. No obstante, es precisamente la utilización de sendos ejemplos lo que puede cuestionar estos planteamientos, aunque quizás el argumento contrario más decisivo sea la inexistencia de referencias literarias a esta supuesta "liga de Gadir", mientras que por contra son numerosos los testimonios escritos que no sólo no la avalan sino que la contradicen. Solamente las emisiones monetales, tardías por otro lado, con el tipo de Melqart y los atunes, puedan aludir a esta posible koiné política liderada por Gadir, aunque para muchos autores sea una manifestación exclusivamente económica y/o religiosa (Chaves y García 1991). Vamos a analizar uno por uno los razonamientos que nos llevan a cuestionar algunos aspectos de la propuesta:

1) Creemos que el papel político de la Gadir de época púnica se ha sobredimensionado por la distorsión provocada por los testimonios escritos de época romana, por la sobrevaloración del peso de la "industria" de salazones de pescado en el conjunto de la economía gaditana y en las relaciones con Grecia, y por el prestigio del santuario de Melqart durante la Antigüedad clásica. La importancia política de Gadir fue, en nuestra opinión, más simbólica que real, y su renombre se debió en gran parte a su situación geográfica, en los límites de la ecumene y a las puertas del Océano. Hubo un evidente interés científico en época helenística por determinados fenómenos naturales (ocultamiento del sol, mareas), por las distancias y referencias a la navegación (stelai de Heracles) y por la geografía de las islas, a la par que un proceso de mitificación de Occidente y de traslados de mitos a una región liminar como era el estrecho de Gibraltar; de ahí que floreciera una corriente especulativa basada en la identificación y ubicación de personajes y lugares descritos en los relatos homéricos y en obras mitológicas (Gerión, Eritia).

Pero no debemos olvidar que las referencias a $G a$ dir en las obras anteriores a la conquista romana son escasas y siempre relacionadas con su situación geográfica, con la evemerización de mitos y con las actividades marineras. Sin ánimo de ser exhaustivos, en las informaciones más antiguas, hasta el siglo V a.C., hay un predominio sintomático de las noticias relacionadas con la identificación o la cercanía entre Gadir y la mítica Eritia ${ }^{10}$, a la que siguen en número la fama de sus productos piscícolas ${ }^{11} \mathrm{y}$ discusiones sobre temas geográficos $^{12}$. El panorama no cambia en los siglos posteriores hasta la conquista romana: el periplo del PseudoEscilax solo refiere la situación de Gadira en dos islas, en una de las cuales se ubica la ciudad, situada a una singladura de las Columnas de Heracles ${ }^{13}$. Del mismo modo las referencias directas a la obra perdida de Timeo aluden a aspectos muy generales, como el nombre dado a la isla de Gadir $^{14}$, su fundación en una península por los fenicios, junto a las Columnas de Heracles, y la riqueza de su templo ${ }^{15}$, o bien su integración en el mito, al vincular la ciudad con la expedición de los Argonautas y las "señales visibles del viaje de regreso en el interior de Gadir"16. La noticia indirecta de Éforo (en Plinio NH 4.120) sobre el nombre -Eritea-dado a Gades, se puede incluir en este grupo.

Podemos decir que la imagen de Gadir transmitida por la historiografía griega anterior a la conquista romana ${ }^{17}$ es paupérrima, fruto del desconocimiento y del desinterés por los asuntos occidentales ${ }^{18}$, y se pueden

10. En Estesícoro de Himera (THA IIA 16c), Ferécides (THA IIA 26b), Heródoto (4.8; THA IIA 37a) y Platón (Critias 108 e Rivaud, THA IIA 57b)

11. Hipócrates recomienda para los enfermos de gota y del bazo la mojama de Gadir (THA IIA 47a), también alabada por los comediógrafos Eúpolis (THA IIA 47b) y Antífanes (THA IIA 47b).

12. Es el caso de Arístides (THA IIA 21b), que refiriéndose al problema de las fuentes del Nilo, se burla de Eutímenes de Marsella argumentando que las aguas que circundan Gadir no son dulces ni potables, pues ni los pescadores de las proximidades de la isla ni los cartagineses que navegan allende las Columnas de Heracles lo mencionan. Por otro lado, Píndaro (THA IIA 30a) aconseja "poéticamente" no navegar a poniente de Gadir.

13. THA IIB $61^{\mathrm{a}}$ (Periplus, 1). “... y, frente a ella, las islas $\mathrm{Ga}-$ dira. Desde Cartago hasta aquí, hasta las Columnas de Heracles, el tiempo de navegación es de una travesía excelente de siete días y siete noches. GADIRA. Son islas próximas a Europa. Una de ellas tiene una ciudad, por allí se encuentran las columnas de Heracles (THA IIB 61d: Periplus, 111)

14. La llama Afrodisias, en Plinio (NH 4.120). El mismo nombre, y en la misma cita de Plinio, es empleado por Sileno, autor de la segunda mitad del siglo III a.C. (THA IIB 75a).

15. THA IIB 67h (en Diod. 5.20.1-4).

16. THA IIB 67e (en Diod. 4.56.3).

17. La literatura posterior, aunque abundante, incide una y otra vez en los mismos aspectos hasta la Antigüedad tardía e incluso hasta época bizantina, convertidos ya en topoi literarios: la vinculación con los trabajos de Hércules y la identificación con Eritia, su situación junto a las columnas hercúleas y en el océano, el santuario de Heracles (Briareo, egipcio, tirio), la supuesta intención de conquista de Alejandro de la costa libia hasta Gadeira, etc. Consultar las voces Gadir, Gadeira, Gadira, Gades en THA IIB.

18. La crítica en Ferrer (1996) y García Fernández (2003) 
resumir en la noción de una fundación tiria de carácter liminar, fronteriza, de ahí su proximidad a las Columnas de Heracles $^{19}$, y por lo tanto lugar de partida y meta de exploraciones y periplos (Eutímenes, Hannón, Himilcón, Piteas, Eudoxo), pero también medio idóneo de acogida de mitos y de especulaciones evemeristas. No disponemos, pues, de datos literarios que permitan aseverar un papel político rector de Gadir sobre los territorios occidentales, lo cual no quiere decir que no lo tuviera, sino que los griegos contemporáneos no lo percibieron así. Por el contrario, sí apreciaron las afamadas salazones y salsas saladas de pescado gadiritas, pero en un contexto muy determinado, el caricaturizado en las comedias. El surgimiento en Grecia de una clase social con capacidad para demandar cantidades crecientes de productos caros, entre ellos el pescado y sus derivados, y el gusto por las comidas lujosas, "ofrecía incontables situaciones cómicas para ridiculizar sus ansias de trufé y sus hipócritas pretensiones de conducta virtuosa" (García Vargas y Ferrer 2005: 19-20).

2) El contexto mediterráneo en el que se integró $G a$ dir tampoco da pie a la consideración de un papel hegemónico de la ciudad en el Mediterráneo occidental. La comparación con la liga ático-délica invita a revisar los motivos que originaron la formación de la liga y las relaciones entre Atenas, líder indiscutible de la liga, y sus aliados. No disponemos de espacio para analizar este fenómeno histórico, pero sí para apuntar que la génesis de la "Liga de Delos" se debió, al menos en principio, a la defensa contra los persas, y que para ello fue imprescindible la construcción de una gran flota financiada por todos los estados con barcos o con contribuciones en dinero. La política de Atenas, caracterizada como epicracia (Nenci 1981: 91), no dudó sin embargo en mostrarse coercitiva con sus aliados más rebeldes, contra los que no dudó en utilizar la fuerza y los propios recursos de la liga (Accame 1941; Meigss 1972; Chankowski 2001).

La púnico-gaditana, de existir, debió definirse contra una amenaza externa, no necesariamente venida del mar, y/o en defensa de los intereses económicos comunes a todos los estados miembros; asimismo, la hegemonía de Gadir tuvo que basarse no sólo en el prestigio del santuario de Melqart y en una cierta autoridad moral asumida por ser la fundación tiria más importante y probablemente más antigua, matriz de otras muchas colonias, sino también en aquellos medios económicos y militares que le posibilitarían mantener esa autoridad en el tiempo. Sin embargo, no hay noticias de que ni

19. Sobre el papel de las stelai en la Antigüedad, Semple (1931).
Gadir ni ninguna otra ciudad púnica de Iberia dispusiese de una flota de guerra ${ }^{20}$, sino de hippoi, pequeños barcos de pesca, y de naves mercantes; y precisamente cuando la ciudad se vio amenazada por "pueblos vecinos" ${ }^{21}$, fue Cartago la que acudió en su ayuda.

La liga ático-délica nos sirve ahora como modelo para esbozar lo que pudo ser una "liga púnica" en la que el papel hegemónico seguramente debió recaer, por lo menos desde mediados del siglo IV a.C., en Cartago y no en Gadir $^{22}$. La paridad política entre las dos ciudades es más ilusoria que real pues todos los acontecimientos relacionados con ambas indican lo contrario: el aludido episodio de la ayuda cartaginesa y posterior conquista del territorio, el tratado firmado entre Roma y Cartago hacia 348 a.C. (Polibio: Hist., 3.22.1-13; THA IIB 76g), el desembarco de Amílcar en Gadir y la posterior actuación de los Barca constituyen los argumentos de más peso pero no los únicos para valorar la disimetría en las relaciones entre ambos estados. Nuevamente acudimos a la literatura griega para constatar que la noción que los griegos coetáneos tenían de las tierras y aguas extremo-occidentales fue transmitida principalmente a través de los cartagineses a partir del siglo V a.C., lo cual indicaría que, aunque podría tratarse de una imagen elaborada interesadamente por éstos, los griegos tenían solo un conocimiento superfluo de la realidad etnográfica y política de esta parte de Iberia, y que las relaciones directas con las ciudades griegas no fueron tan sistemáticas como habitualmente se piensa, ni por supuesto provocaron una "helenización" de Gadir (Millán 1998: 99 ss.).

20. Tan sólo tenemos noticia de la ayuda prestada por los gaditanos a César en 61 a.C. con motivo de las campañas contra los lusitanos (Casio Dión 37.53.2-4). J. Millán (1998: 162) ha estimado que César debió recibir entre 80 y 90 navíos de carga para el transporte unos 18000 hombres preparados para ocupar la isla donde se habían refugiado los insurgentes. También César (B.C. 2.18.1.4) refiere la orden dada por el legado pompeyano Varrón a los gaditanos para equipar diez barcos de guerra. Sobre la flota de la Gades tardorrepublicana, G. Chic (2004: n. 98 y 99).

21. THA IIB 126b (Epitome, 44.1-5).

22. Las referencias más antiguas disponibles, las de Hecateo de Mileto (h. 500 a.C.), aluden a ciertas poleis mastienas como Sialis (THA IIB 142bz), Sixo (THA IIB 142cb), Menobora (THA IIB 142bj) y Molibdina (THA IIB 142bl), identificables las tres primeras con fundaciones fenicias. El etnónimo empleado, mastianos, puede aludir al liderazgo de una supuesta ciudad denominada Mastia según Esteban de Bizancio (THA IIB 142bf) (Ferrer y Bandera 1997), o mejor, al territorio que ocupaban, vecino de los tartesios, Massia según Teopompo (THA IIB 64b) (Ferrer 2006). De estos datos podemos deducir que a fines del siglo VI a.C., los jonios tenían la idea de que el Extremo Occidente estaba organizado políticamente en distintas poleis, no solo mastienas sino también tartesias y de otras etnias, sin que ninguna referencia permita deducir el liderazgo de Gadir (Ferrer 1998). 
El desconocimiento de las tierras occidentales es reconocido por Heródoto (4.196), quien sin embargo describe el "comercio silencioso" practicado por los cartagineses en las tierras de Libia, allende las Columnas de Heracles, que habría escuchado de boca de aquellos. En el periplo de Pseudo-Escilax (Periplus, 111: THA IIB 61d) las distancias en jornadas en el área del estrecho de Gibraltar tienen como referencia a Cartago 23 , y en otro paraplo se señala que "desde las Columnas de Heracles que están en Europa hay muchos establecimientos comerciales cartagineses" ( $P e$ riplus, 1; THA IIB 61a). Por su parte, en los Mirabilia del pseudo-Aristóteles hay tres episodios relacionados con las actividades atlánticas de los púnicos norteafricanos: fenómenos maravillosos de fuegos permanentes "al otro lado de las Columnas de Heracles", según se relataba en el periplo de Hannón ${ }^{24}$ (Mirabilia, 37; THA IIB 66b), el descubrimiento por los cartagineses de una isla desierta en el Océano y sus tretas para no dar publicidad al hallazgo (Mirabilia, 84; THA IIB 66b) ${ }^{25}$, y el transporte de ciertos salazones de calidad por los fenicios de Gadira a Cartago, "los únicos que no explotan los cartagineses, ya que por la calidad que tienen como alimentos, los consumen ellos mismos" (Mirabilia, 136; THA IIB 66h), lo cual lleva implícito que Cartago negociaba con las producciones gadiritas en su beneficio.

Todos estos testimonios, anteriores a la conquista romana, son muy explícitos en lo que respecta al desconocimiento y al desinterés generalizado de los griegos por las tierras occidentales. Los datos que transmiten están insertos casi siempre dentro de "visiones de periplo", esto es, tienen su origen en relatos de viajeros y cartas náuticas y, a partir del siglo IV a.C., en los periplos literarios; en otras ocasiones podían proceder de los prontuarios conservados en santuarios, como el caso de Hannón, depositado en el templo de Cronos (Baal Hammón) de Cartago. El de Melqart en Gadir debió ser un centro de custodia e investigación de temas de muy diversa índole, entre ellos relatos de viajes y cartas náuticas (Marín y Jiménez 2004: 227).

23. Ver nota 14. La cronología deducida por las referencias internas sitúa su redacción hacia 338-335 a.C. (González Ponce 2004: 62).

24. Los periplos de Hannón e Himilcón por las costas atlánticas de África y Europa respectivamente son difíciles de datar pero dan una idea del papel de Gadir como puerto que ejerció la función de meta de periplos mediterráneos y punto de partida de travesías oceánicas, como señala Plinio $(N H, 2.168-169$; THA IIB 98a), pero también del interés del estado cartaginés en los dominios oceánicos (Ferrer 2004). La problemática de sus cronologías, atribuida por la mayoría con anterioridad al 485 a.C., en González Ponce (2004: 68).

25. Este relato coincide en parte con otro referido por Diodoro Sículo (5.20.1-4), pero atribuido a Timeo (THA IIB 67h).
Queda claro que la difusión de muchos de estos conocimientos sobre el Extremo Occidente tuvo como mediadores a los cartagineses quienes, desde el siglo $\mathrm{V}$ a.C. constituían el nexo de comunicación habitual entre Grecia e Iberia a través de una red de puertos en las islas de Sicilia, Cerdeña, Ibiza, y probablemente en el sureste de Iberia (Baria). Las buenas relaciones entre Atenas y Cartago contribuyen a reafirmar esta impresión (Vattuone 1977; Walbank 1985) ${ }^{26}$.

El liderazgo de Cartago en una hipotética "liga púnica" tendría una expresión difícilmente obviable en el tratado de 348 a.C., una evidencia no por repetida menos válida de la hegemonía cartaginesa sobre las tierras occidentales, al tener Cartago la capacidad de legislar en su nombre y en el de sus aliados ${ }^{27}$ sobre la defensa de unos territorios situados más allá de Mastia y de Tarseyo, o lo que es lo mismo, más allá de la costa mediterránea y del estrecho de Gibraltar ${ }^{28}$. La capacidad de respuesta de Cartago ante las agresiones a sus aliados se pondría de manifiesto en el oscuro episodio del ataque sufrido por Gadir que Justino epitomó de tal manera que se hace imposible datarlo y poder establecer las causas. Lo cierto es que los intereses cartagineses en la zona debieron ser decisivos porque la ayuda prestada se constituyó en una excusa para intervenir directamente en territorio hispano ${ }^{29}$.

Si la documentación literaria nos parece concluyente, el registro arqueológico no hace sino confirmar la injerencia cartaginesa en una zona de interés estratégico para Gadir. Los tesorillos de moneda cartaginesa acuñada en Sicilia y Cerdeña ocultados a fines del

26. Nenci (1981: 91) compara la epicracia ateniense con la púnica: "se trata de hecho de una superioridad dirigida a la creación de regímenes afines y de un área común de intercambios, obtenida con todos los medios disponibles en la época (diplomacia, presencia o intervenciones militares, propaganda ideológica)... No es casualidad que pudiera realizarse el acercamiento al mundo púnico y fenicio, con los cuales compartían la vocación mercantil, que va siempre acompañada de una renuncia a conquistar territorios, del deseo de relaciones pacíficas para favorecer los intercambios,...”.

27. El tratado hace referencia a aliados de Cartago, entre ellos Útica y los tirios, quienes algunos autores han identificado con los fenicios occidentales o los habitantes de Gadir como principal fundación tiria (Tsirkin 1996: 145; Koch 2001: 193-194; López Castro 2004: 157), atribución que nos parece sumamente problemática (Ferrer 2006).

28. Recientemente P. Moret (2002) ha propuesto que Mastia fuese un topónimo norteafricano y Tarseyo de Cerdeña, atendiendo a la coherencia interna del tratado. No obstante, defendemos que ambos topónimos se ubicarían en Iberia, y concretamente Mastia, según el testimonio de Teopompo (THA IIB 64b), en el litoral mediterráneo de la actual Andalucía (Ferrer 2006).

29. "Entonces con una expedición afortunada no sólo vengaron a los gaditanos de la injusticia sino que añadieron la mayor parte de la provincia a su gobierno" (Epitome, 44.5; THA IIB 126b). 
siglo IV o principios de siglo III a.C. en El Gandul (Alcalá de Guadaíra, Sevilla) han sido interpretados como un indicio de la existencia de campamentos cartagineses cuya función sería la contratación de mercenarios turdetanos (Pliego 2001, 2003 y 2005). No obstante, la existencia de otros tesorillos con millares de monedas de los mismos tipos e idéntica cronología en Cerros de San Pedro (Fuentes de Andalucía, Sevilla), nos ha hecho pensar en la posibilidad de que estos campamentos formaran parte también de una estrategia de control y coerción contra Carmo, la plaza fuerte más importante de Turdetania (Ferrer 2007).

3) Gadir era uno de los puertos comerciales más importantes de Mediterráneo occidental, pero no era una ciudad extensa ni dominaba un vasto territorio. Según Estrabón (3.5.3.) los gaditanos vivían en un principio en una ciudad muy pequeña, pero Balbo les construyó otra que llamaron "Nueva". El mismo pasaje estraboniano hace alusión a los dominios de la ciudad fenicia cuando, refiriéndose a los habitantes de las Gadeira, dice que "puesto que no habitan una isla grande ni dominan extensas tierras en la parte opuesta de la costa firme, ni poseen otras islas, la mayoría viven en la mar, siendo pocos los que residen en sus casa o están en Roma" ${ }^{30}$. Ciertamente es un dato tardío, de la Gades tardorrepublicana, pero puede dar una idea del dominio sobre un territorio no muy extenso en tierra firme que probablemente sería respetado tras el foedus firmado con Roma en 206 a.C. Si a este dato le sumamos otra noticia nuevamente transmitida por Estrabón (3.2.2.) en la que dice que en Asta, "los gaditanos se suelen reunir a menudo, ya que no está mucho más de cien estadios del arsenal de la isla" 31 , podríamos llegar a la conclusión de que la influencia política gaditana también se extendería a esta importante ciudad situada no lejos de Gadir, en los esteros, cuyo registro arqueológico muestra evidentes concomitancias con el púnico-gaditano. Sin embargo, el pasaje es lo suficientemente problemático, según señala $\mathrm{G}$. Chic (1994: 401), como para sacar conclusiones tan aventuradas.

Una consideración restrictiva de los dominios de la Gadir prerromana incluiría tan sólo la costa de la bahía, con el Castillo de Doña Blanca, el poblado de Las

30. A partir de García y Bellido (1983: 176).

31. Esta es la traducción de García y Bellido (1983: 70); la versión de G. Chic (1994: 392) reza lo siguiente: "entre los célticos (la ciudad) más conocida es Conistorgis, en los esteros Asta, en la que 'los que en este momento son gaditanos' se reúnen la mayor parte de las veces, encontrándose situada por encima del puerto de la isla a no mucho más de cien estadios".
Cumbres $^{32}$ y las factorías de salazones del litoral portuense hasta los límites territoriales indefinidos de Asta, por el norte, y quizás de Asido, al este, que son las ciudades más importantes del entorno ${ }^{33}$. Asta, titulada Regia (en Plinio NH 3.11), como se infiere del decreto de Paulo Emilio (CIL II, 5041), era un estado territorial a comienzos del siglo II a.C. que extendía su dominio sobre un territorio relativamente extenso apoyándose en una serie de turres, como la lascutana, y quizás también Seguntia (Chic 1987: 26), que le servían de defensa y desde las que se controlaba a una plebs servilis que trabajaba en condiciones de inferioridad respecto a la población dominante ${ }^{34}$.

Este parece ser el tipo de formación política en el entorno de Gadir: los pequeños estados territoriales con fronteras inestables y procesos embrionarios o ya consolidados de urbanización, en los que la ciudad fenicia debió actuar como fermento y como modelo. Las prospecciones arqueológicas superficiales en el entorno de la bahía de Cádiz y en los esteros del sinus tartesius $^{35}$ parecen confirmar esta impresión. Los centros de poder tenían su sede en oppida como Nabrissa, Eboura, Asta Regia, Asido o Baesippo ${ }^{36}$, desde donde organizaban unos territorios más o menos extensos defendidos por atalayas y explotados desde asentamientos menores. Pero las prospecciones no pueden dar cuenta de fenómenos que de no ser por la documentación epigráfica o literaria no serían apercibidos, como el dominio

32. No debemos olvidar que ambos asentamientos se despueblan coincidiendo con la segunda Guerra Púnica o con el término de ésta. Sus excavadores (Ruiz Mata y Pérez 1995: 75) proponen una cronología de 215-210 a.C. para el abandono por el tesorillo de monedas cartaginesas de cobre, y apuntan como explicación la presencia romana y el aluvión del río Guadalete, que dificultaría la navegación por la zona. No obstante, los mismos autores documentaron en las excavaciones estratos de incendio, bolas de catapulta y cadáveres de caballos y de hombres en el exterior de la muralla, lo que puede dar idea de un fin violento para el asentamiento. Sin embargo, esta explicación sería contradictoria con la ventajosa política romana hacia $\mathrm{Ga}$ $d i r$, en el caso de que CDB y Las Cumbres fuesen dominios continentales de la ciudad. Cabe la posibilidad-silenciada por las fuentes en este caso- de que se llegase a un acuerdo con Roma después de sufrir las amenazas y agresiones que acabaron con estos asentamientos.

33. Refiriéndose a la ordenación territorial de la bahía de Cádiz en época romana, G. Chic (2004) destaca el establecimiento de dos colonias, Hasta Regia y Asido Caesarina, cuyos territorios limitarían con el de Gades; el de Asido llegaría hasta Puerto Real y el de Hasta no incluiría el litoral del Puerto de Santa María.

34. Hay una abundante bibliografía sobre el epígrafe, entre otros Mangas (1997), García Moreno (1986), Hidalgo (1989) y López Castro (1994).

35. Lebrija, Las Cabezas de San Juan, Dos Hermanas, Jerez de la Frontera, Sanlúcar de Barrameda, Vejer de la Frontera. Un estudio general del poblamiento turdetano en el Bajo Guadalquivir en F.J. García Fernández (2003).

36. Sobre el territorio de Baesippo, uid. Ferrer (e.p.). 
político de unos sobre otros según se aprecia en el caso de Asta Regia con la Turris Lascutana.

No cabe duda de que los procesos de urbanización fueron potenciados por la presencia bárcida y por la conquista romana (Bendala 1989 y e.p.); sin embargo no eran fenómenos desconocidos en el Suroeste sino que partían de una tradición centenaria vinculada a la colonización fenicia (Onuba, Ilipla, Tejada la Vieja, CDB). Asimismo estos pequeños estados embrionarios tenían un claro precedente en las poleis tartesias y mastienas que Hecateo de Mileto (c. 500 a.C.) dio a conocer en su Periégesis. En el entorno del estrecho de Gibraltar, además de las mastienas, el milesio ubicó algunas poleis adscritas a territorio tartesio como Ibila (THA IIA 23i) y Elibirge (THA IIA 23h), y otra, Calate (THA IIA 23a $)^{37}$, sin filiación étnica conocida pero "no lejos de las Columnas de Heracles".

Lógicamente estas poleis convivieron con otras formaciones sociales basadas en el parentesco y sin atisbos de urbanización. Como señala G. Chic (1998: 299 ss.), la transición de "un tipo de sociedad basada en los lazos establecidos por la sangre a otra en que la relación hombre-territorio es dominante lógicamente es muy lenta y es normal que nos encontremos coexistiendo elementos de uno y otro tipo".

\section{BIBLIOGRAFÍA}

ACCAME, S. (1941): La lega ateniese del sec. IV a.C. Roma.

ALFARO ASINS, C. (1991): "Epigrafía monetal púnica y neopúnica en Hispania. Ensayo de síntesis", Ermanno A. Arslan Studia Dicata. Glaux 7, I: 109156.

- (1998): "Las emisiones feno-púnicas", Historia monetaria de Hispania Antigua: 50-115. Madrid.

ARRUDA, A.M. (1999-2000): Los fenicios en Portugal. Cuadernos de Arqueología Mediterránea 5-6. Barcelona.

- (2005): "A ocupacao pré-romana de Faro: alguns dados novos", Revista Portuguesa de Arqueología 8, 1: 177-208.

ARTEAGA MATUTE, O. (1990): “La formación del mundo púnico", Historia de España: 456-469. Ed. Planeta, Barcelona.

- (1994): "La liga púnico gaditana. Aproximación a una visión histórica occidental, para su contrastación con el desarrollo de la hegemonía cartaginesa, en el mundo mediterráneo", Cartago, Gadir, Ebusus y la

37. Éforo también la cita como Calatusa ( $F H A$ IIA 23a). influencia púnica en los territorios hispanos. VIII Jornadas de Arqueología fenicio-púnica: 23-57. Ibiza.

- (2001): "La emergencia de la 'polis' en el mundo púnico occidental", Protohistoria de la Península Ibérica: 217-281. Ed. Ariel, Barcelona.

BANDERA, Ma.L. de la y FERRER, E. (1995): "Reconstrucción del ajuar de una tumba de Cástulo ¿indicios de mestizaje?", Arqueólogos, historiadores y filólogos. Homenaje a Fernando Gascó. Kolaios 4: 53-65.

BELÉN, Ma . y ESCACENA, J.L. (1995): “Interacción cultural fenicios-indígenas en el Bajo Guadalquivir", Kolaios 4: 67-101.

BENDALA GALÁN, M. (1989): "La génesis de la estructura urbana en la España antigua", CuPAUAM 16: $127-147$

- (2005): "Urbanismo y romanización en el territorio andaluz: Aportaciones a un debate en curso", Mainake XXVII: 9-32.

BERNAL, D.; DÍAZ, J.J.; EXPÓSITO, J.A.; SÁEZ, A.M.; LORENZO, L. y SÁEZ, A. (2003): Arqueología y urbanismo. Avance de los hallazgos de época púnica y romana en las obras de la carretera de Camposoto (San Fernando, Cádiz). San Fernando.

BERNAL, D.; SÁEZ, A.; DÍAZ, J.J.; EXPÓSITO, J.A.; LORENZO, L.; SÁEZ, A. y GARCÍA, R. (2005): "Gadir y la manufactura de máscaras y terracotas. Aportaciones del taller isleño de Villa Maruja", $M a$ drider Mitteilungen 46: 61-86.

CARRETERO POBLETE, P.A. (200 ): “Difusión de ánforas tipo 'Tiñosa' en Algarve (Portugal) y la comercialización de productos agrícolas púnico-turdetanos entre los siglos V y III a.C.", Actas do Encontro de Arqueología do Algarve. Xelb 5: 305-316.

CHANKOWSKI, V. (2001) : “Athénes, Délos et les Cyclades á l'époque classique: Un réseau économique ", REA 103 : 83-102.

CHAVES TRISTÁN, F. (2000): “LLa monetización de la Bética desde las colonias púnicas?", Los cartagineses y la monetización del Mediterráneo occidental. Anejos de AEspA XXII: 113-126.

CHAVES, F. y GARCÍA VARGAS, E. (1991): "Reflexiones en torno al área comercial de Gades: Estudio numismático y económico", Gerión. Homenaje al Dr. Michel Ponsich: 139-168.

- (1994): “Gadir y el comercio atlántico a través de las cecas occidentales de la Ulterior", Arqueología en el entorno del Bajo Guadiana: 375-392. Huelva.

CHAVES, F.; GARCÍA VARGAS, E. y FERRER, E. (1998): "Datos relativos a la pervivencia del denominado 'Círculo del Estrecho' en época 
republicana", L'Africa Romana. Atti del XII Convegno di Studio: 1307-1320. Sassari.

CHAVES, F.; GARCÍA FERNÁNDEZ, F.J. y FERRER, E. (2006): "Relaciones interétnicas e identidades culturales en Turdetania (siglos II a.C.-I d.C.)", L'Africa romana. Atti del XV Convegno di Studio: 813-828. Roma.

CHIC GARCÍA, G. (1987): "La campaña de Catón en la Ulterior. El caso de Seguntia”, Gades 15: 23-27.

- (1994): "Lucubraciones en torno al conuentus de Hasta (Estrabón, III, 2, 2. 141", Homenaje al Profesor Francisco J. Presedo Velo: 391-402. Sevilla.

- (1998): "La transformación de los sistemas de convivencia: Hacia la formación de las urbes en el sur de Hispania", J. Mangas (ed.), Italia e Hispania en la crisis de la República. Actas del III Congreso Hispano-Italiano: 295-306. Madrid.

- (2004): "La ordenación territorial en la bahía de Cádiz durante el Alto Imperio romano", Revista de Historia de El Puerto 33: 11-50.

CRUZ ANDREOTTI, G. (1993): "Estrabón y el pasado turdetano: la recuperación del mito tartésico", Geographia Antiqua 2: 13-31.

CRUZ ANDREOTTI, G. y MORA SERRANO, B., coords. (2004): Identidades étnicas - Identidades politicas en el mundo prerromano. Málaga.

DOMÍNGUEZ PÉREZ, J.C. (2003): "Entidad arqueológica y dimensión económico-política del Círculo Púnico-Gaditano en el Mediterráneo Occidental, 348-218 a.C.", Antiquitas 15: 51-58.

- (2005): "Gallaecia Poena. Avance para una definición no esencialista del Hierro Final noroccidental", Gallaecia: 35-60.

ESCACENA CARRASCO, J.L. (1989): "Los turdetanos o la recuperación de la identidad perdida", Tartessos. Arqueología Protohistórica del Bajo Guadalquivir: 433-476. Sabadell.

- (1992): "Indicadores étnicos en la Andalucía prerromana", Spal 1: 321-343. http://dx.doi. org/10.12795/spal.1992.i1.16

FERNÁNDEZ NIETO, F.J. (1992): “Griegos y colonización griega en la Península Ibérica”, F. Chaves (ed.), Griegos en Occidente: 129-145.

FERREIRO LÓPEZ, M. (1982): “Asta Regia según los geógrafos antiguos”, Gades 9:155-177.

FERRER ALBELDA, E. (1995-96): “Anotaciones sobre el taller cerámico de Gadir", Boletín del Museo de Cádiz VII: 63-76.

- (1996a): La España Cartaginesa. Claves historiográficas para la historia de España. Sevilla.

- (1996b): "Los púnicos de Iberia y la historiografía grecolatina", Spal 5: 115-131. http://dx.doi. org/10.12795/spal.1996.i5.06
- (1998): "Suplemento al mapa paleoetnológico de la Península Ibérica: los púnicos de Iberia”, $R S F$, XXVI, 1: 31-54.

- (2000): "Nam sunt feroces hoc libyphoenices loco: ¿Libiofenicios en Iberia?", Spal 9: 421-433. http:// dx.doi.org/10.12795/spal.2000.i9.23

- (2002-2003): “Gloria y ruina de la Iberia cartaginesa. Imágenes del poder en la historiografía española", CuPAUAM 28-29: 7-21.

- (2004a): "Sustratos fenicios y adstratos púnicos: Los bástulos entre el Guadiana y el Guadalquivir", Huelva Arqueológica 20: 281-298.

- (2004b): "Los púnicos de Occidente y el Atlántico", FORTUNATAE INSULAE. Canarias y el Mediterráneo: 39-47. Santa Cruz de Tenerife.

- (2006): “Mastia en Africa?”, L’Africa Romana. XVI Convegno di Studio: 1997-2008. Roma.

— (2007a): "El territorio de la ciudad bástulo-púnica de Baesippo", III Coloquio Internacional del Centro de Estudios Fenicios y Púnicos. Las ciudades feniciopúnicas en el Mediterráneo Occidental, Adra, e.p.

- (2007b): "Fenicios y cartagineses en el Tartessos postcolonial", Actas del V Congreso sobre Historia de Carmona. El nacimiento de la ciudad: La Carmona protohistórica: 195-223. Carmona.

FERRER, E. y BANDERA, M‥L. de la (1997): "La localización de Mastia: un aspecto problemático de los conocimientos geográficos griegos sobre Iberia", Xaire. Homenaje al Prof. F. Gascó: 65-72. Sevilla.

FERRER, E. y GARCÍA FERNÁNDEZ, F.J. (2002): "Turdetania y turdetanos: Contribución a una problemática historiográfica y arqueológica", Mainake XXIV: 133-151.

FERRER, E. y GARCÍA VARGAS, E. (2001): "Producción y comercio de salazones y salsas saladas de pescado de la costa malagueña en épocas púnica y romana republicana", Comercio y comerciantes en la Historia Antigua de Málaga (siglo VIII a.C. año 711 a.C. ). II Congreso de Historia Antigua de Málaga: 547-571. Málaga.

FERRER, E. y PRADOS, E. (2001-2002): "Bastetanos y bástulo-púnicos. Sobre la complejidad étnica del sureste de Iberia", Studia E. Cuadrado. AnMurcia 16-17: 273-282.

FERRER, E.; SIBÓN, J.F. y MANCHEÑO, D. (2000): "Máscaras púnicas de Gadir", Actas del IV Congreso Internacional de Estudios Fenicios y Púnicos II: 593-606. Cádiz.

GARCÍA-BELLIDO, Ma.P. (1993): "Las cecas libiofenicias", Numismática hispano-púnica. Estado de la cuestión. VII Jornadas de Arqueología Fenicio-púnica: 97-146. Ibiza. 
GARCÍA FERNÁNDEZ, F.J. (2002): “Turdetania, turdetanos y cultura turdetana", Numismatica e Antichitá Classiche XXXI: 191-202.

- (2002): "Los turdetanos en la historiografía reciente: 25 años de avances y desencuentros", Spal 11:219231. http://dx.doi.org/10.12795/spal.2002.i11.11

- (2003): El poblamiento turdetano en el Bajo Guadalquivir, Tesis Doctoral, Universidad de Sevilla.

- (2003): Los turdetanos en la Historia. Análisis de los testimonios literarios grecolatinos. Ed. Gráficas Sol, Écija.

- (2004): "De Turdetania a Baetica: la imagen de una región paradigmática en la literatura grecolatina", F. Beltrán (ed.), Antiqua Iuniora. En torno al Mediterráneo en la Antigüedad: 111-123. Zaragoza.

- (e.p.): "Etnología y etnias de la Turdetania en época prerromana", CUPAUAM.

GARCÍA MORENO, L.A. (1986): "Sobre el decreto de Paulo Emilio y la Turris Lascutana”, Actas de la Reunión sobre epigrafía hispánica de época romanorepublicana: 195-218. Zaragoza.

GARCÍA VARGAS, E. y FERRER, E. (2005): "Producción y comercio de salazones y salsas saladas de pescado del litoral andaluz en época fenicio-púnica. Temas y problemas", Setúbal Arqueológica 13: $13-32$.

GARCÍA Y BELLIDO, A. (1983 [1945]): España y los españoles hace dos mil años según la "Geografía" de Strábon. Madrid.

GONZÁLEZ PONCE, F.J. (2004): “Tradición literaria y conocimiento científico. Los Periplos en el extremo de Occidente", FORTUNATAE INSULAE. Canarias y el Mediterráneo: 61-70. Santa Cruz de Tenerife.

GONZÁLEZ RUIBAL, A. (2004): "Facing two seas: Mediterranean and Atlantic contacts in the NorthWest of Iberia in the First Millennium BC", Oxford Journal of Archaeology 23, 3: 287-317.

- (2006): "PAst the Last Outpost: Punic Merchants in the Atlantic Ocean (5th-1st centuries BC)", Journal of Mediterranean Archaeology 19, 1: 121-150.

GONZÁLEZ WAGNER, C. (1984): 'El comercio púnico en el Mediterráneo a la luz de una nueva interpretación de los tratados concluidos entre Cartago y Roma", MHA 6: 211-224.

- (1994): "El auge de Cartago (s. VI-V) y su manifestación en la Península Ibérica". Cartago, Gadir, Ebusus y la influencia púnica en los territorios hispanos. VIII Jornadas de Arqueología fenicio-púnica: 7-24. Ibiza.

- (2005): "Consideraciones sobre un nuevo modelo colonial en la Península Ibérica”, El período orientalizante. Actas del III Congreso Inernacional de Arqueología de Mérida: Protohistoria del Mediterráneo Occidental: 149-165.

GRANAYMERICH, J.J. (1991): Malaga Phénicienne et Punique. Recherches franco-espagnoles 1981-1988. Paris.

HIDALGO DE LA VEGA, Mª.J. (1989): "El bronce de Lascuta: un balance historiográfico", Studia Historica. Historia Antigua VII: 59-65.

HUSS, W. (1993): Los cartagineses. Madrid.

$\mathrm{KOCH}, \mathrm{M}$. (2001): "Cartago e Hispania anteriores a los Bárquidas”, Religión, lengua y cultura prerromanas de Hispania: 189-197. Salamanca.

LANCEL, S. (1994): Cartago. Barcelona.

LÓPEZ CASTRO, J.L. (1994): "El bronce de Lascuta y las relaciones de servidumbre en el sur de Hispania”, La sociedad de la Bética. Contribuciones para su estudio: 345-364. Granada.

- (2004): "La identidad étnica de los fenicios occidentales”, G. Cruz Andreotti y B. Mora (eds.), Identidades étnicas-Identidades políticas en el mundo prerromano hispano: 147-167. Málaga.

MANGAS, J. (1977): "Servidumbre comunitaria en la Bética prerromana”, MHA I: 151-161.

MARÍN, M․C. y JIMÉNEZ, A.Ma . (2004): "Los santuarios fenicio-púnicos como centros de sabiduría: El templo de Melqart en Gadir", Huelva Arqueológica 20: 215-240.

MARTÍN CAMINO, M. y ROLDÁN, B. (1991): "Aportación al conocimiento de la presencia fenicia y púnica en el litoral del sudeste peninsular", XX CNA: 355-361. Zaragoza.

MARTÍN RUIZ, J.A. (2004): Los fenicios en Andalucía. Sevilla.

MAS, J. (1985): "El polígono submarino de Cabo de palos. Sus aportaciones al estudio del tráfico marítimo antiguo", VI Congreso Internacional de Arqueología Submarina: 153-171. Madrid.

MEDEROS, A. y RUIZ CABRERO, L.A. (2004): “El pecio fenicio del Bajo de la Campana (Murcia, España) y el comercio del marfil norteafricano", Zephyrus LVII: 263-281.

MEIGGS, R. (1972): The Athenian Empire. Oxford.

MORET, P. (2002): "Mastia Tarseion y el problema geográfico del segundo tratado entre Cartago y Roma", Mainake XXIV: 257-276.

NENCI, G. (1981): "Formación y naturaleza del imperio ateniense", Historia y civilización de los griegos. Grecia en la época de Pericles. Historia, literatura, filosofía III: 50-91. Barcelona.

NIVEAU DE VILLEDARY, A.M". (1999): "La cerámica 'tipo Kuass': Avance a la sistematización del taller gaditano", Spal 8: 115-134. http://dx.doi. org/10.12795/spal.1999.i8.07 
— (2000): "La producción de cerámicas rojas de tradición griega en la zona de Cádiz. Las cerámicas tipo 'Kuass': una nueva perspectiva”, MM 41: 178-196.

- (2001): "El espacio geopolítico gaditano en época púnica. Revisión y puesta al día del concepto de "Círculo del Estrecho",, Gerión 19: 313-354.

- (2003): Cerámicas gaditanas "tipo Kuass”. BRAH, Madrid.

PLIEGO VÁZQUEZ, R. (2001): La circulación monetaria prerromana en el área de El Gandul. Memoria de Licenciatura inédita, Universidad de Sevilla, 2001.

- (2003): "Sobre el reclutamiento de mercenarios turdetanos. El campamento cartaginés de El Gandul (Alcalá de Guadaíra, Sevilla)", Habis 34: 39-56.

PLIEGO VÁZQUEZ, R. (2005): “Un nuevo conjunto monetal cartaginés procedente de El Gandul (Alcalá de Guadaíra, Sevilla)", Actas del XIII Congreso Internacional de Numismática, I: 531-533. Madrid.

PONSICH, M. (1975): "Perennité des relations dans le circuit des Détroit de Gibraltar", Aufstieg und Niedergang de römischen Welt II: 651 ss. Berlin.

RUIZ MATA, D. (1987): "La formación de la cultura turdetana en la bahía de Cádiz a través del Castillo de Doña Blanca", Iberos. Actas de las I Jornadas sobre Mundo ibérico: 299-314. Jaén.

- (1997): "Fenicios, tartesios y turdetanos", La Andalucía Ibero-turdetana (siglos VI-IV a.C.). Huelva Arqueológica XIV: 325-367.

- (1998): "Turdetanos: origen, territorio y delimitación del tiempo histórico", Revista de Estudios Ibéricos III: 153-221.
- (2001): “Arquitectura y urbanismo en la ciudad protohistórica del Castillo de Doña Blanca (El Puerto de Santa María, Cádiz)", Arquitectura oriental y orientalizante en la península ibérica: 261-274. Madrid.

RUIZ MATA, D. y PÉREZ, J.Ma. (1995): El poblado fenicio del Castillo de Doña Blanca. El Puerto de Santa María.

SÁEZ, A. y DÍAZ, J.J. (2002): "La industria alfarera de Gadir. Talleres y producciones", Revista de Arqueología 252: 50-55.

SEMPLE, E. C. (1931): The Geography of the Mediterranean region. Its relation to Ancient History. New York

SOLÁ-SOLÉ, J.M. (1980): El alfabeto de las cecas "libiofenices". Barcelona.

TARRADELL, M. (1960): Marruecos púnico. Tetuán. - (1967): "Los nuevos documentos", en D. Harden, Los fenicios: 279-314. Barcelona.

- (1968): "Economía de la colonización fenicia", Estudios de economía antigua de la Península Ibérica: 81-97.

TSIRKIN, I.B. (1996): “The downfall of Tartessos and the Carthaginian establishment in the Iberian Peninsula", RSF XXIV: 141-152.

VATTUONE, R. (1977): 'L'alleanza fra Atene e Cartagine alla fine del V sec. a.C. (IG, I, $47+S E G, \mathrm{X}$, 136)", Epigraphica XXXIX: 41-50.

WALBANK, M.B. (1985): "Athens, Carthage and Tyre (IG ii2 342+)", Zeitschrift Für Papyrologie und Epigraphik 59: 107-111. 